\title{
Guidelines for Interviewing Children During Child Custody Evaluations
}

\author{
MARTINE B. POWELL \\ Deakin University, Australia \\ SANDRA LANCASTER \\ Monash University, Australia
}

$\mathrm{T}$

his paper offers a brief review of the current literature related to the interviewing of children during child custody evaluations. In particular, the paper highlights several key issues and concerns, and provides a series of recommendations for professionals working in this area. These recommendations (which apply to children aged 3 to 12 years) are organised under the following headings: (a) establish rapport using broad open-ended questions, (b) make the purpose and ground rules of the interview clear to the child, (c) allow the child's perspective be heard without expecting an outright custody preference, (d) demonstrate a willingness to consider all reasonable perspectives or hypotheses about what has occurred, (e) try not to exacerbate the child's stress or guilt, (f) pursue all possible explanations for a child's report, irrespective of whether there are clear signs of "coaching" or contamination, $(\mathrm{g})$ obtain appropriate training in the use of forensic interviewing techniques, and ( $h$ ) engage in research on the impact of children's participation in custody cases.

Psychologists and other mental health professionals are frequently called upon by the courts to serve as evaluators in child custody cases. Such evaluations are among the most complex and challenging assessments conducted by these professionals and carry a high risk of complaints to registration boards about possible malpractice (Glassman, 1998; Montgomery, Cupit \& Wimberly, 1999; Kirkland \& Kirkland, 2001). Contested custody cases (which are usually those cases referred to psychologists for evaluation) are often complicated by intense family conflict, allegations of misconduct, parental mental illness and severe psychological disturbance (Oberlander, 1995). The difficulty in conducting custody assessments is also complicated by a lack of standardised techniques or guidelines on which to base recommendations (Grisso, 1986). Instead, psychologists must rely on their expertise and training in various areas such as child development, conflict resolution, ethical issues and advanced psychological assessment (Brodzinsky, 1993; Kuehnle, 1998, Hynan, 1998), as well as the many articles and books which discuss possible factors to consider when conducting such evaluations (e.g., Ackerman, 1995; Karras \& Berry, 1985; Stahl, 1994; Schutz, Dixon, Lindenberger \& Ruther, 1989).

Despite an abundance of literature on the topic of custody evaluation, relatively little discussion has focused on the process of interviewing children during custody evaluations (see Hynan, 1998). This is surprising given that child interviews are a central part of custody evaluations, with at least several hours typically being spent by psychologists interviewing children (Ackerman \& Ackerman, 1997; Bushard, 1995). Further, the issue of interviewing children in forensic contexts is not an area in which psychologists have considerable expertise and training (Powell, 2002), Interviewing children for therapeutic purposes is very different from interviewing children for forensic purposes and even those guides written by experts in custody evaluation (e.g., Ackerman, 1995; Schutz et al., 1989; Stahl, 1994) do not fully acknowledge issues regarding the accuracy of children's statements in forensic interview contexts. Indeed the focus of discussion on interviewing children in most custody evaluation guides is on specifying the precise information that needs to be obtained. What is often overlooked is that the process of eliciting information about events from children is just as critical as the information obtained, especially when the child's social skills, language and cognitive capacity are limited (Poole \& Lamb, 1998; Wilson $\&$ Powell, 2001). The lack of discussion on the issue of forensic interviewing of children is a critical factor underpinning the controversy surrounding the value of involving children in custody evaluations and the quality of information obtained from them (McGough, 1994).

While it is clear that children are more vulnerable than adults to poor questioning techniques, research over the past few decades has clearly identified ways of maximising the amount and accuracy of information obtained from children. The current paper provides a list of key recommendations that are considered by experts as essential for eliciting reliable and detailed information from children for the purpose of any forensic evaluation. These recommendations apply to children aged 3 to 12 years and include the following practical principles: (a) establish rapport using broad open-ended questions, (b) make the purpose and ground rules of the interview clear to the child, (c) allow the child's perspective to be heard (without expecting an outright custody preference), (d) demonstrate a willingness to consider all reasonable perspectives or hypotheses about what has occurred, (e) try not to exacerbate the child's stress or guilt, (f) pursue all possible explanations for a child's report, irrespective of whether there are clear signs of "coaching" or contamination. Two recommendations are 
also provided for increasing professional expertise. These include: (a) obtain appropriate training in the use of forensic interviewing techniques, and (b) engage in research on the impact of children's participation in custody cases. A rationale for the importance of each of these recommendations within the context of custody evaluations is provided, as well as practical advice and further reading where appropriate. ${ }^{1}$

\section{Establish Rapport with the Child Using Broad Open-ended Questions}

A good child-interviewer rapport, which is synonymous with the establishment of a supportive, nonjudgmental and child-centered conversational environment, is considered by most psychologists as one of the most important assets to an interviewer (Wilson \& Powell, 2001). The greater the rapport between the child and the interviewer, the more information the child is likely to share and the more likely the child will reveal the depth of his needs, wishes, knowledge and desires (Goodman, Rudy, Bottoms, \& Aman, 1990; Siegal, 1991). This is especially true when the child is discussing sensitive information about family issues. Divorce is usually disrupting and confusing for children and frequently they will at some level blame themselves for the break-up of the family. Many will exhibit signs of stress associated with the divorce and an interviewer will need to have an understanding of the underlying causes of such stress in order to establish rapport, elicit appropriate information and evaluate a child's responses. The typical fears that children experience in the context of a parental separation are related to change, loss of attachment, fear of abandonment and hostility between their parents. For children, divorce means that the family will be different, their responsibilities and routines may change, and they may lose contact with friends or members of the extended family.

Bowlby (1979) has noted that "many of the most intense of all human emotions arise during the formation, the maintenance, the disruption and renewal of affectional bonds" (p. 27). While parents are a child's main attachment figures, children also have strong attachments to siblings, peers and pets. Any changes (actual or anticipated) in the amount of contact with attachment figures can cause distress for the child. Loss of attachment is closely linked to fear of abandonment. Young children (because of their intense dependence on parents) may be more likely to link this fear to worry about practical situations articulated in questions such as "Who will make my breakfast?", "Who will take me to school?" and so forth. Some children will also have experienced stress as a result of hostility between their parents. Children who have been caught in the middle of their parents' struggle and have been encouraged to take sides become confused and may express consequent feelings of sadness, anxiety and anger through words or actions. Of course the fears described above cannot just be considered in terms of the current situation but must also be understood in the context of the child's experiences prior to the parental separation. In other words, children who have had insecure attachments or been exposed to longstanding marital conflict are likely to be more vulnerable.

Children's understanding of divorce is dependent on age. In young children particularly, fantasies about the parents getting back together may continue for a long time. Older children have a better understanding of divorce but may have strong family loyalties that make them reluctant to trust those who they may see as interfering in their lives. All of these factors are likely to influence the child's willingness to confide in the interviewer and make it critical that interviewers spend enough time establishing rapport.
A child-centered and supportive conversational environment is considered so important by experts on interviewing children that a discrete "rapport-building" phase is included in most prominent investigative interview protocols for children (see Poole \& Lamb, 1998, for a review).

Field research has shown that most practitioners attempt to build rapport with the child by spending a few minutes prior to the main interview asking a series of direct or focused questions about the child's school, family and/or favourite activities (Berliner \& Lieb, 2001; Sternberg, Lamb, Davies \& Westcott, in press; Warren, Woodall, Hunt \& Perry, 1996). For example, Sattler (1998) suggested questions such as "What's your favourite subject in school?", "What things in your home do you like?" "What do you and your friends like to do?" (p. 936). Research, however, suggests that asking multiple questions of this nature can inhibit the establishment of a supportive child-centered conversational environment. Direct or focused questions tend to elicit only brief responses from children rather than elaborate information and they imply that the interviewer's job is to tell the child specifically what information about the child's life is relevant, interesting and important (Sternberg et al., 1997). Further, when asking specific questions, it is difficult for the interviewer not to display attitudes, beliefs or prior knowledge about the child (Ceci \& Bruck, 1993). When children think adult interviewers know about their situation, they are less likely to come forth and disclose information (Toglia, Ross, Ceci \& Hembrooke, 1992). To encourage children to talk during the rapportbuilding phase it is often more fruitful to ask non-focused open-ended questions centered around an enjoyable activity or event that the child has experienced (Orbach et al., 2000). For example an interviewer could say to a child, "Before we talk about... I want to get to know you a little better. A few weeks ago, it was the school holidays. Think about your school holidays and tell me everything you can remember about them". Once the child has identified several main activities, the interviewer could then use minimal prompts to elicit more information about one or two of the activities (e.g., "You said you went to Sea World. Tell me what happened at Sea World from the beginning to the end", "What else can you tell me about Sea World?", "What happened then?").

There are three main advantages of an open-ended style of interaction in the rapport-building stage. First, an openended questioning style provides a better gauge of the child's cognitive and linguistic level compared to specific questions. Knowledge of children's developmental level is essential for phrasing questions appropriately (Poole \& Lamb, 1998). Second, an open-ended style of interaction during the rapport-building phase enhances the quality and elaborateness of children's subsequent responses during the main part of the interview (see Sternberg et al., 1997). Third, an open-ended style enhances children's social status and provided the interviewer demonstrates good listening skills and avoids displaying attitudes or beliefs about the child or the event in question, it shows the child that he or she can respond openly and honestly without judgement or pressure (Powell \& Thomson, in press). For more information on the value of an open-ended rapport building style refer to Sternberg et al., (1997).

\section{Make the Purpose and Ground rules of the Interview Clear to the Child}

Children are more likely to provide reliable, relevant and detailed information in forensic interviews when they have a clear understanding of their role and the purpose of the 
interview (Siegal, 1991). These issues need to be explained as specifically as possible but in a manner that is appropriate to the child's level of development. Vague descriptions of the purpose (e.g., "My job is to help you and let you have your say", "I need you to help your parents with their plans") carry the risk that the child will subsequently relate irrelevant information or responses that do not provide an accurate representation of the depth of the child's knowledge and opinions. The need for clearer explanations of the purpose of involving children in custody evaluations is highlighted by survey research which shows that the majority of children who are involved in conciliation and custody litigation are confused about the nature and impact of their involvement, even in cases where evaluators attempted to explain these issues with them (Garwood, 1990; Kalternborn, 2001).

One useful approach suggested by Sattler (1998) is to ask children what they know about the reason for the interview. This provides an indication of what the child has been told by the parents and gives the evaluator the opportunity to clear up any misconceptions the child may have. Subsequently, the interviewer should provide a clear description of the purpose of the interview and each person's role in it. Issues to be clarified include: (a) the format of the interview (i.e., it involves "talking" with the focus being to help the interviewer learn about the child), (b) the topics to be discussed, (c) people who will be present throughout the meeting, (d) limits (if any) concerning confidentiality and (e) the relative impact of the child's statement and consequences that may follow from it. In relation to this latter issue, children sometimes feel betrayed or angry when the outcome of a custody litigation does not coincide with their stated wishes (Kaltenborn, 2001). It should be made clear to the child at the outset of the interview that the judge will make the custody decision by weighing up all the evidence and that the decision does not rest solely with the child. These issues could be outlined verbally prior to, or at the outset of the meeting. Alternatively, they could be provided to older children in the form of an explanatory leaflet (Garwood, 1990).

Information also needs to be provided about the ground rules of the interview. Keeping children informed of the ground rules lets them know how to behave in the interview. This is important because the process and expectations of a forensic interview are very different from other interviews children typically experience (e.g., interviews with school teachers). Table 1 displays a list of the ground rules that are frequently misunderstood by children in forensic interviews and provides recommendations for overcoming these misunderstandings.

\section{Allow the Child's Perspective be Heard Without Expecting an Outright Custody Preference}

There is no question that children's wishes are relevant and important to custody determinations and that they have the right to play an active role in decisions about their future (Crosby-Currie, 1996). However, it is the ethical obligation of professionals to ensure that this occurs in a manner that takes into account children's developmental capacities (Kuehnle, 1998). An understanding of different developmental stages, and the processes of attachment is not only crucial to how the interview is conducted but also to an understanding of children's responses. While children as young as 4 years of age can provide forensically reliable and detailed information, their ability to make honest and reliable judgements when asserting custodial preference is determined by a wide range of factors. These factors include the child's memory, intellectual and linguistic capacity (and susceptibility to social influences), the type of questions asked (and responses expected) and the contextual factors related to the interview setting and family conflict (see Crossman, Powell, Principe \& Ceci, 2002).

Overall, three major arguments have been proposed in the literature to qualify concerns about the reliability of children's judgements when asserting custody preference.

\section{TABLE 1}

Common Misunderstandings in Forensic Interviews Involving Children

\begin{tabular}{ll}
\hline Misunderstanding & Recommendation \\
\hline Children often withhold information because they believe adults know & It needs to be stressed that the interviewer does not know about the \\
that information already. This is especially the case when the inter- & child's views and/or situation and the interviewer needs the child's \\
viewer has spoken to other family members previously. & $\begin{array}{l}\text { help to understand it. The interviewer could say "Even if you think I } \\
\text { already know something, tell me anyway". }\end{array}$
\end{tabular}

Children do not know what types of details are relevant in custody assessments and may omit details because they are not perceived to be important.

Children may not believe it is acceptable to say "I don't know", or "I don't understand".

When a question or part thereof is repeated in an interview, many children assume that the initial response was incorrect and therefore a change of response is desired.

In many contexts in which children speak to adults, it is not acceptable to use slang, swear words or sexually explicit language.
It should be explicitly stated when discussing a particular topic that any information the child provides about that topic might be useful. The child can say anything that comes to mind, even things that the child does not think are important

It needs to be made explicit that the child can correct the interviewer if he/she misunderstands something, and that "I don't know", or "I don't understand" are acceptable responses to questions.

Repeated questions should be avoided. If a question needs to be asked again, it should be reworded. Also, the interviewer could say "If I ask a question again, it doesn't mean I want you to change your answer. Just tell me what you remember the best you can."

The child should be informed in the interview that (s)he can use any words that (s)he wants to, and that the interviewer will not be shocked, angry or upset by what the child says.

The child should be told that it is important to tell only what he/she knows or remembers.
Children might provide information merely to placate the interviewer or to tell the interviewer what he/she thinks he/she wants to hear.

Note: Adapted from Wilson \& Powell (2001), Garwood (1990), and Siegal (1991). 
First, decisions about custody often evoke overwhelming feelings of disloyalty, guilt, betrayal and a sense of responsibility in the child, even at a very young age (Rosen, 1977). Asking a child to state outright which parent is their preferred primary caregiver places the child in the untenable position of having to reject one parent. Because of this winlose approach, the child's comments may be more governed by what should be said or what decision would cause the least hurt or negative consequences for the child and family. The detrimental effect of these influences can be minimised to some degree by assuring the child confidentiality in his or her opinion (Crosby-Currie, 1996). However, confidentiality would not necessarily prevent social and motivational factors from influencing children's responses. A child may choose a parent because that parent is viewed as the most needy or least responsible for the divorce, irrespective of the amount of overt pressure that has been placed on the child to do so (Maloney \& Byrne, 1993; Sattler, 1998).

Second, decisions about custody are complex and need to be based on the weight of many factors such as parenting capacity and availability, the child's current as well as future physical and psychological needs, environmental factors and the quality of the relationships between the child and prospective custodians (Sattler, 1998). Although children at least 9 years of age can demonstrate the potential ability to consider such factors when making decisions about custodial preference (see Garrison, 1991), children's limited linguistic, cognitive and social/emotional development make it difficult for them to know and to articulate what is in their best interests and to have a realistic understanding of the immediate and long-term consequences of their preferences. Reasons offered by children for their choices provide useful insight into their capacity to make a judgement, and the degree to which their statements are fuelled by sympathy, anger, disillusionment or duress (see Oberlander, 1995). Third, concerns are often relayed about the possibility that parents in some way shape the perceptions of their children during divorce and that children's custody decisions reflect the opinion of the more influential parent rather than the child (Gardner, 1992; Byrne, 1989).

In conclusion, because the dynamics of cases varies considerably, the extent and nature of the child's involvement and the weight that is placed on the child's custodial preference (if provided) needs to be determined on a caseby-case basis. Unless custodial preference is readily articulated, however, children should not be pressured into making a choice (Garrison, 1991). If a choice is made, the child's apparent preferences need to be considered as only one part of the entire situation and should be treated with a certain degree of caution (Maloney, 1995; Renouf, 1990).

So how could the child's perspective be heard without placing him or her in a loyalty bind, and without expecting the child to make an outright choice? Children can contribute to the decision-making process by responding to a basic set of questions which provides a sense of the quality of the child's relationship with the parents and extended family, the nature (and anticipated pros and cons) of each parents' current life situation, the child's daily home and school routine, and the child's feelings about divorce and custody (see Ackerman, 1995; Chasin \& Grunebaum, 1981; Heller \& Derdeyn, 1979; Sattler, 1998). Justifiably, this approach puts the onus on the interviewer to ensure that appropriate questioning strategies are used that are matched to the child's developmental level and that allow the depth of the child's knowledge to be maximised and his or her reasoning examined. Consideration of the appropriateness of the child's reasoning is crucial for determining how much weight the child's views should play within the entire context of the evaluation.

\section{Demonstrate a Willingness to Consider all Reasonable Perspectives or Hypotheses About What Has Occurred}

A common problem that arises in custody evaluations is when professionals violate the boundaries of their role as independent evaluators (Kuehnle, 1998). Any interview conducted for the purpose of gathering accurate and reliable information from a child must be regarded as an exercise in testing hypotheses, not a confirmation of what the interviewer already thinks or knows (Melton, Petrila, Poythress \& Slobogin, 1997). Research has shown that when an interviewer is biased, or thinks he or she knows the truth about the nature of an event or an individual, relevant or vital information is overlooked, screened out, or ignored, and the information elicited from the child is less likely to be complete and accurate (Ceci \& Bruck, 1995). The potential risk of misunderstanding is heightened when the child and family identify with a cultural group that is different from that of the interviewer (see Powell \& Bartholomew, in press).

The issue of confirmation bias is particularly relevant to custody decisions because these decisions are inherently subjective and value laden. For example, personal bias has been shown to predict the type of custody arrangements favored by mental health professionals with some professionals preferring to award custody to parents of one gender over the other (see Woody, 1977). Further, common practices such as working with only one parent as opposed to being an independent evaluator, or relying on custody evaluation referrals from lawyers, can minimise the professionals' ability to remain objective (Foster, 1983). As Karras and Berry (1985) stated, custody evaluators often "seem to be swept into the adversarial system. Instead of offering opinion concerning the outcomes of alternative arrangements the court may use in making decisions, many evaluators make strong custodial judgements" (p. 77). Because of this concern, some professionals recommend that solicitors only choose experts who insist on being involved only as an impartial examiner from the outset (Byrne, 1989; Lee, Beauregard \& Hunsley, 1998). While this creates a greater risk that an opinion will be offered that does not favour the client, it enhances the possibility of obtaining an opinion which is genuinely in the best interests of the child.

An impartial examiner, however, is not so easily identified without a record of the person's interviewing style and approach to the investigation. The qualities of a non-biased interviewer in a custody evaluation are as follows:

- They genuinely seek and consider all available evidence, not merely information that confirms their beliefs or opinions.

- They let the child do most of the talking and avoid leading and suggestive and closed questions that control the child's answers.

- They try to establish a relationship where the child can correct for misunderstanding.

- They try to establish how much the child's responses are constrained by limited language skills, a desire to please the interviewer, loyalty conflicts and attachments.

- They base their conclusions on a systematic approach and do not always rely on shortcuts. 
- They accept any type of response the child provides regardless of whether the response is consistent with the beliefs or the opinions of the interviewer.

- They do not pressure the child to talk.

- They acknowledge the numerous ways that cultural variables impact on the interview and assessment process.

- They try to establish the possible source of information acquired (i.e., whether it was actually observed or learned first-hand by the child or was merely talked about).

Without a record of the interview, the only way of knowing if the examiner has these qualities is to examine his or her credentials and the nature and quality of any training in forensic interviewing techniques. It is therefore important to provide specialised short courses or training for qualified psychologists wishing to engage in this work and to also ensure that university courses in forensic psychology place more emphasis on child interviews.

\section{Be Cautious Not to Exacerbate the Child's Stress or Guilt}

The main goals of a child forensic interview with a child is to elicit reliable and detailed information in a manner that minimises stress or trauma on the child. Potential stressors and individual reactions to stress vary markedly among children. For example, children's reactions to questions about custody in an interview will vary depending on their age, personalities, their attributions of responsibility, the degree of trauma and abuse in the home, children's perception of the demands of the situation, their relationships and experiences with the parents and the persons who are present in the interview. As noted above, children often hold themselves responsible for what has happened in the family. Though they may experience a number of fears about their future as a consequence of the family break-up, they may also feel a strong need to protect a parent who they perceive as vulnerable. Psychologists need to be sensitive to these issues and conduct the interview in a way that does not exacerbate the child's stress or guilt.

In light of the complexity of factors underlying children's experience of and reactions to stressors, judgements about the ways of minimising the child's level of stress within the interview need to be made about each child individually. For example, in cases where it appears that an older child has been sworn to secrecy, it might be helpful for the interviewer to allow the child to get past fears of talking before eliciting details about the matter (MacFarlane \& Krebs, 1986). However, for some children who appear hesitant to talk, it is more productive to open the emotionally charged topic with factual questions before the child's fears and feelings are explored (Powell $\&$ Thomson, 1994). In general, children will be more reluctant to disclose when a family member is present. However, in cases where issues have already been discussed with the parents, the child may not mind speaking openly and honestly in front of the parents.

When attempting to minimise the child's stress, it is important to keep in mind that the purpose of the interview is investigative rather than therapeutic in nature. As far as possible the forensic interviewer must respond in a neutral manner avoiding comments that aim to be therapeutic (e.g., reassuring the child that it wasn't his or her fault). Such comments could be detrimental to the evidence. Responses to children's comments should be limited, therefore, to general counselling techniques such as summarising or reflecting. The purpose of these techniques is to merely indicate to the child that his or her messages have been heard accurately. Importantly, any evidence of stress observed when interviewing the child should be noted in the psychologist's report along with any identified needs of the child and recommendations for how these needs should be addressed.

\section{Pursue all Possible Explanations for a Child's Report, Irrespective of Whether There Are Signs of Parental Coaching}

Concerns are frequently expressed that parents can shape the perceptions of their children during divorce (Byrne, 1989; Gardner, 1999; Radin, 1984). While for most parents, divorce does not significantly disturb relationships with their children, in its extreme form, parental influence has been equated to "brainwashing" (Gardner, 1992). If a parent has an intense, persistent desire to get the child to agree with his or her negative views and uses repeated suggestive and misleading interview techniques, it is possible that the child could adopt similarly biased views and beliefs and could be led to make false accusations of wrongdoing directed at one of the parents (Leichtman \& Ceci, 1995; Poole \& Lindsay, 1995). This is especially the case with young children (i.e., preschoolers; Ceci \& Bruck, 1993). To attempt to compensate for pressure and bribery, Oberlander (1995) recommended that at least two interviews with the child should take place, giving each parent the opportunity to transport the child to the interview. While such a solution may seem to have merit, it ignores the fact that parental influences are much more likely to be subtle and insidious. Depending on the child's current situation the recommended arrangement could also be more stressful for the child.

The general difficulties of conducting child custody evaluations are compounded when a parent is accused of sexually abusing one or more of the children (Awad, 1987; Cooke \& Cooke, 1991, Kuehnle, 1998; Mitnick. 1983). It must be kept in mind, however, that the presence of any factors indicative of coaching should have little impact on the seriousness, quality and thoroughness of an investigation into a child's claims of abuse. There is currently no scientifically valid way of determining whether a child's statement is true or false (Lamb, Sternberg, Esplin, Hershkowitz \& Orbach, 1997; Poole \& Lindsay, 1998). The use of adult language by the child (e.g., "My father violated my body") does not mean that the account is fabricated as these expressions could have been obtained by the child subsequent to a spontaneous disclosure of abuse. Behaviour that is consistent with a parent's accusations could be the result of "brainwashing" but some divorces are the result of abuse allegations not vice versa. In fact, child sexual abuse is alleged in only a small proportion (i.e., $2 \%$ ) of custody disputes through the courts, and research suggests that in approximately half of the court cases where abuse is alleged to occur during a custody visitation dispute, the evidence is consistent with or likely to be abuse (Thoennes \& Tjaden, 1990). Further, a lack of specific details in a child's account may be because the allegation was made up, but it may also be the result of normal developmental or memory limitations (Roberts \& Powell, 2001). Therefore, if it appears that a child has been put up to an allegation of abuse or other harm, evaluators should (as they would typically do) interview the child without the parent present to try to get a sense of the context of the allegation, and check out competing hypotheses that may explain it. ${ }^{2}$ 


\section{The Necessity for Appropriate Training in the Use of Forensic Interviewing Techniques}

Research has consistently demonstrated that the most reliable, accurate and detailed information obtained from children about events or situations is that which is elicited with the use of open-ended questions. This is especially the case when children are allowed to relate their account of an event or situation in their own words, at their own pace and without interruption. Ideally, an account proceeds with the interviewer providing a general or open-ended question, for example "Tell me about what happens when you stay at Joe's house" and then subsequently using minimal nonverbal encouragers (e.g., head nods, pauses, "Mmmm", silence, "Uh-huh") or further open-ended questions (e.g., "Tell me more about that." , "What happened then?", What else can you tell me about...?") to gently encourage the child to provide further information. The importance of these prompts is that they are general; they focus the child on a broad topic (i.e., being at Joe's house). In contrast, specific questions (e.g., "Who makes your breakfast?", "Do you have your own room?", "Does anyone else live with Joe?", "What happens at bath time?") tend to dictate what specific information is required.

There are four major benefits of using an open-ended interviewing style (as opposed to multiple specific questions) when questioning children about a situation or event. First, responses to open-ended questions are usually more accurate compared to responses to specific questions (Cole \& Loftus, 1987; Dent \& Stephenson, 1979). Second, specific and closed (e.g., yes/no, forced choice) questions can mask poor comprehension and misunderstanding as children can adopt strategies to cover up their limitations (in order to appear competent conversational partners). Strategies include: repeating back phrases or words used by the interviewer, providing a stereotypical response, or providing affirmative answers to yes/no questions even if the child does not understand them (Aldridge \& Wood, 1998; Poole \& Lindsay, 1995). For example, asking the child "Who told you to say that?" (a technique sometimes used in custody evaluations to elicit information about parental influence on the child's statements; Oberlander, 1995) presumes that the child was told to say the statement by somebody. If the child did not remember being told the statement, he or she might provide the name of a person merely because he or she presumes that the interviewer would not have asked the question unless there was a correct answer. Inviting the child to say "I don't know" does not prevent false responses resulting from the pressures of interviewer demand characteristics or suggestion (Moston, 1987). Third, swift questioning does not allow the interviewer and the child time to collect their thoughts, and as a consequence, does not lend itself to elaborate memory retrieval (Lamb et al., 1996; Wade \& Wetscott, 1997). Finally, when the interviewer imposes his or her language and framework on the situation, there is greater potential for confusion or misunderstanding (Brennan \& Brennan, 1990).

Despite the advantages of open-ended questioning strategies, research indicates that professionals do not use them effectively in their everyday practice (Sternberg, Lamb, Davies, \& Westcott, in press). The use of open-ended interviewing requires special training and quality control evaluation, not merely an understanding of the vulnerabilities of interviewees and an awareness of the techniques that may be used to overcome these (Lamb et al., in press). As indicated earlier, interviewing children for forensic purposes is very different from interviewing children for therapeutic purposes, yet psychologists receive very little appropriate training and practice in the use of forensic interviewing techniques (Powell, 2002). Concerns about the quality of questioning performed by custody evaluators has led some psychologists to recommend that all interviews with children about custody preferences be recorded on audio- or video-tape (Siegal, 1991). Indeed, if psychologists choose to work in this area, they should be willing and able to demonstrate knowledge and competency in the area in which they profess to have expertise (Kuehnle, 1998).

Training in the use of forensic interviewing techniques can usually be obtained through specialist workshops at conferences or by approaching child protection units to elicit the names of local experts who conduct ad hoc workshops on interviewing children. Advice can also be obtained from books which provide clear practical guidelines for interviewing (e.g., Poole \& Lamb, 1998; Wilson \& Powell, 2001). However, research has consistently shown that knowledge in how to interview children has little impact on actual job performance without multiple opportunities for practice and corrective evaluation (see Powell, 2002, for review). To become expert interviewers of children, long-term training via ongoing supervision in a group or one-to-one situation is required rather than merely attending a single training course.

\section{Engage in Research on the Impact of Children's Participation in Custody Cases}

There is a dearth of research on children's participation in custody evaluations. Therefore, little is known about many of the presumptions that currently guide legal practice. Relevant issues that need to be examined include: the reliability of (and the value of confidentiality on) children's stated preferences, how children's wishes affect the decisions judges make, the best person(s) to conduct assessments of children, and the psychological effect of children's involvement in custody litigation, especially when their stated preferences are ignored (Oberlander, 1995). Until we learn more about these aspects, more specific recommendations than those offered in the current manuscript should be taken with caution.

The importance of basing practice on empirical research as opposed to personal opinion and anecdotal experience cannot be overestimated. For example, one of the common rationales provided by professionals for excluding children from court procedures is that they are negatively affected by direct involvement in the custody decision-making process (see Crosby-Currie, 1996). In contrast, one of the best-designed studies on this issue showed the opposite; that involvement in custody-litigation actually enhanced the development of children's adaptive coping strategies (Wolman \& Taylor, 1991). While one cannot make generalisations on the basis of any single research study, this finding highlights the importance of keeping an open mind and of conducting and disseminating research that tests the presumptions that guide our practice.

Conducting research in this area, however, involves a great deal of commitment, resources, funding and planning. There may also be methodological limitations imposed by legal statutes that control the release of information obtained in the course of an evaluation in respect of Family Court cases. Also, to examine the impact of children's involvement, it is necessary to tease out the effect of legal proceedings per se from the emotional, financial and physical stresses associated with the family's upheaval, divorce and inter-parental battle (Wallerstein, 1991). This requires longitudinal designs that allow comparisons of baseline and post-test responses and samples of children from 
contesting and non-contesting families matched on a number of demographic variables.

\section{Summary}

The elicitation of reliable and accurate information from a child during a custody evaluation is a complex process that depends in part on the interviewer applying several important skills. These skills include the ability to use openended questioning strategies, to develop rapport with the child, to keep an open mind, and to provide a clear description of the purpose and ground rules of the interview. Psychologists need to have specialist training in order to develop the skills required for the forensic interviewing of children. Well-trained interviewers are more likely to obtain useful and reliable information that reflects the true depth of children's knowledge and beliefs. Further, information obtained by well-trained interviewers is subsequently more useful for the courts when making custody decisions that are in the best interests of the child. With regard to legal process, psychologists should also assist by conducting research on the value and impact of children's participation in custody evaluations. To date, there is little empirical evidence to support many of the presumptions that guide legal practice.

\section{Endnotes}

1 Given the confines of this review we discuss issues pertaining to the process of interviewing solely rather than what constitutes a full psychological assessment of a child during a custody evaluation or specific areas of content that are needed to form an opinion about custody arrangements. Further, we do not address in depth issues related to children's development and how this affects the way they communicate in an interview and the appropriateness of various questioning strategies. For information in relation to this latter issue, refer to Wilson and Powell (2001), Walker (1999) or Poole and Lamb (1998).

2 Obviously, the case would need to be referred to a professional who is mandated to interview a child about sexual abuse (i.e., a police officer or child protection worker).

\section{References}

Ackerman, M.J. (1995) Clinician's guide to child custody evaluations. New York: John Wiley \& Sons.

Ackerman, M.J., \& Ackerman, M.C. (1997). Custody evaluation practices: A survey of experienced professionals. Professional Psychology: Research and Practice, 28, 137-145.

Aldridge, M., \& Wood, J. (1998). Interviewing children: A guide for child-care and forensic practitioners. Chichester: John Wiley \& Sons.

Awad, G. (1987). The assessment of custody and access disputes in cases of sexual abuse allegations. Canadian Journal of Psychiatry, 32(7), 539-544.

Berliner, L., \& Lieb, R. (2001). Child sexual abuse investigations: Testing documentation methods. Washington: Washington State Institute for Public Policy.

Bowlby, J. (1979). The making and breaking of affectional bonds. London: Tavistock Publications.

Brennan, M., \& Brennan, R.E. (1990). Strange language: Child victims under cross examination (3rd ed.). Wagga Wagga: Riverina Literacy Centre.

Brodzinsky, D. (1993). On the use and misuse of psychological testing in child custody evaluations. Professional Psychology: Research and Practice, 24(2), 213-219.

Bushard, P. (1995). Interviewing children. In P. Bushard \& D.A. Howard (Eds.), Resource guide for custody evaluators (pp.
1-13). Madison, WI: Association of Family and Conciliation Courts.

Byrne, K. (1989). Brainwashing in custody cases: The Parental Alienation Syndrome. Australian Family Lawyer, 4(3), 1-5.

Ceci, S.J., \& Bruck, M. (1993). The suggestibility of the child witness: A historical review and synthesis. Psychological Bulletin, 113, 403-439.

Ceci, S.J., \& Bruck, M. (1995). Jeopardy in the courtroom: A scientific analysis of children's testimony. Washington, DC: American Psychological Association.

Chasin, R., \& Grunebaum, H. (1981). A model for evaluation in child custody disputes. American Journal of Family Therapy, 9(3), 43-49.

Cole, C.B., \& Loftus, E. (1987). The memory of children. In S.J. Ceci, M.P. Toglia, \& D.F. Ross (Eds.), Children's eyewitness memory (pp. 178-208). New York: Springer-Verlag.

Cooke, G., \& Cooke, M. (1991). Dealing with sexual abuse allegations in the context of custody evaluations. American Journal of Forensic Psychology, 9(3), 55-67.

Crosby-Currie, C. (1996). Children's involvement in contested custody cases: Practices and experiences of legal and mental health professionals. Law and Human Behavior, 20(3), 289-311

Crossman, A., Powell, M.B., Principe, G., \& Ceci, S. (2002). Child testimony in custody cases: A review. Journal of Forensic Psychology Practice, 2(1), 1-32.

Dent, H.R., \& Stephenson, G.M. (1979). An experimental study of the effectiveness of different techniques of interviewing child witnesses. British Journal of Social and Clinical Psychology, 18, 41-51.

Foster, H.H. (1983). Child custody and divorce: A lawyer's view. Journal of the American Academy of Child Psychiatry, 22, 392-398.

Gardner, R.A. (1992). The parental alienation syndrome. Cresskill, N. J.: Creative Therapeutics.

Gardner, R.A. (1999). Guidelines for assessing parental preference in child-custody disputes. Journal of Divorce and Remarriage, 30, 1-9.

Garrison, E.G. (1991). Children's competence to participate in divorce custody decisionmaking. Journal of Clinical Child Psychology, 20, 78-87.

Garwood, F. (1990). Children in conciliation: The experience of involving children in conciliation. Family and Conciliation Courts Review, 28(l), 43-51.

Glassman, J.B. (1998). Preventing and managing board complaints: the downside risk of custody evaluation. Professional Psychology: Research and Practice, 29(2), 121-124.

Goodman, G.S., Rudy, L., Bottoms, B.L., \& Aman, C. (1990). Children's concerns and memory: Issues of ecological validity in the study of children's eyewitness testimony. In R. Fivush \& J.A. Hudson (Eds.), Knowing and remembering in young children (pp. 249-284). New York: Cambridge University Press.

Grisso, T. (1986). Evaluating competencies. New York: Plenum.

Heller, J.R., \& Derdeyn, A.P. (1979). Child custody consultation in abuse and neglect: A practical guide. Child Psychiatry and Human Development, 9, 171-179.

Hynan, D. (1998). Interviewing children in custody evaluations. Family and Conciliation Courts Review, 36(4), 466-478.

Kaltenborn, K. (2001). Children's and young people's experiences in various residential arrangements: A longitudinal study to evaluate criteria for custody and residence decision making. British Journal of Social work, 31(1), 81-117.

Karras, D., \& Berry, K.K. (1985). Custody evaluations: A critica review. Professional Psychology: Research and Practice, 16. $76-85$.

Kirkland, K., \& Kirkland, K. (2001). Frequency of child custody evaluation complaints and related disciplinary action: A survey 
of the association of state and provincial psychology boards. Professional Psychology: Research and Practice, 32(2), 171-174.

Kuehnle, K. (1998). Ethics and the forensic expert: A case study of child custody involving allegations of child sexual abuse. Ethics and Behavior, 8(1), 1-18.

Lamb, M.E., Hershkowitz, I., Sternberg, K.J., Esplin, P.W., Hovav, M., Manor, T., et al. (1996). Effects of investigative utterance types on Israeli children's responses. International Journal of Behavioral Development, 19, 627-637.

Lamb, M.E. Sternberg, K.J., \& Esplin, P.W., Hershkowitz, I., \& Orbach, Y. (1997). Assessing the credibility of children's allegations of sexual abuse: Insights from recent research. Learning and Individual Differences, 9, 175-194.

Lamb, M.E., Sternberg, K.J., Orbach, Y., Hershkowitz, I., Horowitz, D. \& Esplin, P. (in press). The effects of intensive training and ongoing supervision on the quality of investigative interviews with alleged sex abuse victims. Applied Developmental Science.

Lee, C.M., Beauregard, P.M. \& Hunsley, J. (1998). Lawyers' opinions regarding child custody mediation and assessment services: Implications for psychological practice. Professional Psychology: Research and Practice, 29(2), 115-120.

Leichtman, M.D., \& Ceci, S.J. (1995). The effects of stereotypes and suggestions on preschoolers' reports. Developmental Psychology, 31, 568-578.

MacFarlane, K., \& Krebs, S. (1986). Techniques for interviewing and evidence gathering. In $\mathrm{K}$. MacFarlane \& J. Waterman (Eds.), Sexual abuse of young children: Evaluation and Treatment (pp. 30-51). New York: The Guilford Press.

Maloney, L (1995). Children's rights in family law disputes: Issues of process and outcome. Family Matters, 40, 4-9.

Maloney, L., \& Byrne, K. (1993). It's really up to the children: Intractable access and the professional. Australian Family Lawyer, 8(4), 1-5.

McGough, L. (1994). Child witnesses: Fragile voices in the American legal system, New Haven: Yale University Press.

Melton, G.B., Petrila, J., Poythress, N.G., \& Slobogin, C. (1997). Psychological evaluations for the courts. New York: Guilford Press.

Mitnick, M. (1983). Family sexual abuse and custody evaluation. Conciliation Courts Review, 2l(2), 89-94.

Montgomery, L.M., Cupit, B.E., \& Wimberly, T.K. (1999). Complaints, malpractice, and management: Professional issues and personal experiences. Professional Psychology: Research and Practice, 30, 402-410.

Moston, S. (1987). The suggestibility of children in interview studies. First Language, 7, 67-78.

Orbach, Y., Hershowitz, I., Lamb, M.E., Sternberg,K.J., Esplin, P.W., \& Horowitz, D. (2000). Assessing the value of structured protocols for forensic interviews of alleged child abuse victims. Child Abuse \& Neglect, 24(6), 733-752.

Oberlander, L.B. (1995). Ethical responsibilities in child custody evaluations: Implications for evaluation methodology. Ethics and Behaviour, 5(4), 311-332.

Poole, D.A., \& Lamb, M.E. (1998). Investigative Interviews of Children. Washington DC: American Psychological Association.

Poole, D.A., \& Lindsay, D.S. (1995). Interviewing preschoolers: Effects of non-suggestive techniques, parental coaching, and leading questions on reports of nonexperienced events. Journal of Experimental Child Psychology, 60, 129-154.

Poole, D.A., \& Lindsay, D.S. (1998). Assessing the accuracy of young children's reports: Lessons from the investigation of child sexual abuse. Applied and Preventive Psychology, $7,1-26$

Powell, M.B. (2002). Specialist training in investigative and evidential interviewing: Is it having any effect on the behaviour of professionals in the field? Psychiatry, Psychology and Law, 9, 44-55.

Powell, M.B., \& Bartholomew, T. (in press). Interviewing and assessing clients from different cultural backgrounds: Guidelines for all forensic professionals. In R. Bull \& D. Carson (Eds.), Handbook of psychology in legal contexts.

Powell, M.B., \& Thomson, D.M. (1994). A review of children's eyewitness memory research and its implications for the investigatory interview. Families in Society: Journal of Contemporary Human Services, 75(4), 204-216.

Powell, M.B., \& Thomson, D.M. (in press). The makings of a reliable interview with a child witness. Australian Educational and Developmental Psychologist.

Radin, S. (1984). The relationship of the parental preference guideline to attachment behavior in young children of divorce. Journal of Psychiarry \& Law, 12(4), 473-482.

Renouf, E. (1990). Perspectives on the involvement of dependent children in custody mediation, Australian Journal of Sex, Marriage and Family, 10(3), 107-110.

Roberts, K.P., \& Powell, M.B. (2001). Describing individual incidents of sexual abuse: A review of research on the effects of multiple sources of information on children's reports. Child Abuse and Neglect, 25(12), 1643-1659.

Rosen, R. (1977). Children of divorce: What they feel about access and other aspects of the divorce experience. Journal of Clinical Child Psychology, 6(2), 24-27.

Sattler, J.M. (1998). Clinical and forensic interviewing of children and families: Guidelines for the mental health, education, pediatric, and child maltreatment fields. San Diego: Jerome M. Sattler, Publisher, Inc.

Schutz, B.M., Dixon, E.B., Lindenberger, J.C., \& Ruther, N.J. (1989). Soloman's sword: A practical guide to conducting child custody evaluations. San Francico: Jossey-Bass.

Siegal, M. (1991). Concern for the conversational environment: Questioning children in custody disputes, Professional Psychology: Research and Practice, 22(6), 473-478.

Stahl, P.M. (1994). Conducting child custody evaluations. A comprehensive guide. Thousand Oaks, CA: Sage.

Sternberg, K.J., Lamb, M.E., Hershkowitz, I., Yudilevicth, L., Orbach, Y., Esplin, P.W., et al. (1997). Effects of introductory style on children's abilities to describe experiences of sexual abuse. Child Abuse and Neglect, 21, 1133-1146.

Sternberg, K., Lamb, M. Davies, G.M., \& Westcott, H.L. (in press). The memorandum of good practice: Theory versus application. Child Abuse and Neglect.

Thoennes, N., \& Tjaden, P. (1990). The extent, nature and validity of sexual abuse allegations in custody visitation disputes. Child Abuse and Neglect, 14, 151-163.

Toglia, M.P., Ross, D.F., Ceci, S.J., \& Hembrooke, H. (1992). The suggestibility of children's memory: A social-psychological and cognitive interpretation. In M.L. Howe, C.J. Brainerd, \& V.F. Reyna (Eds.), Development of Long-term Retention (pp. 217-241). New York: Springer-Verlag.

Wade, A., \& Westcott, H. (1997). No easy answers: Children's perspectives on investigative interviews. In H. Westcott \& J. Jones, (Eds.), Perspectives on the Memorandum: Policy, practice and research in investigative interviewing. Arena: Hants.

Walker, A.G. (1999). Handbook on questioning children: A linguistic perspective. Washington: ABA Center on Children and the Law.

Wallerstein, J.S. (1991). The long term effects of divorce on children: A review. Journal of the American Academy of Child and Adolescent Psychiatry, 30, 349-360.

Warren, A.R., Woodall, C.E., Hunt, J.S., \& Perry, N.W. (1996). "It sounds good in theory but...": Do investigative interviewers follow guidelines based on memory research? Child Maltreatment, 1(3), 231-245. 
Wilson, J.C., \& Powell, M.B. (2001). A guide to interviewing children. Sydney: Allen \& Unwin.

Wolman, R., \& Taylor, K. (1991). Psychological effects of custody disputes on children. Behavioural Sciences and the Law, 9, 399-417.
Woody, R.H. (1977). Behavioural science criteria in child custody determinations. Journal of Marriage and Family Counseling, $3(1), 11-18$. 